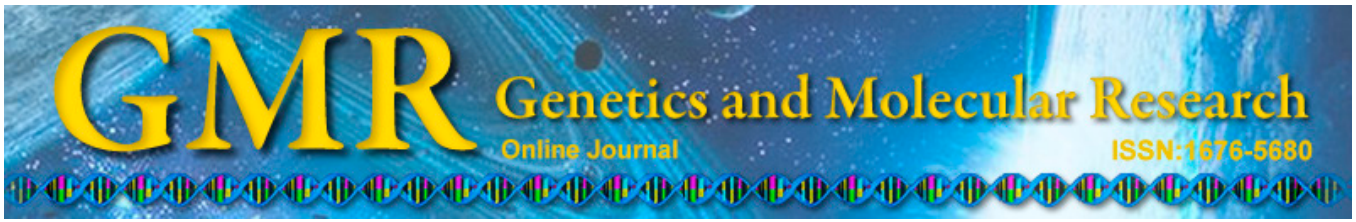

\title{
Inheritance of balanced translocation t(17; 22) from a Down syndrome mother to a phenotypically normal daughter
}

\author{
X.Y. Liu, Y.T. Jiang, R.X. Wang, L.L. Luo, Y.H. Liu and R.Z. Liu \\ Center for Reproductive Medicine, Center for Prenatal Diagnosis, \\ First Hospital, Jilin University, Changchun, China \\ Corresponding author: R.Z. Liu \\ E-mail: 1rz410@126.com
}

Genet. Mol. Res. 14 (3): 10267-10272 (2015)

Received February 4, 2015

Accepted May 24, 2015

Published August 28, 2015

DOI http://dx.doi.org/10.4238/2015.August.28.11

\begin{abstract}
We report that a 30-year-old woman with mental retardation was referred for prenatal diagnoses during pregnancy. An ultrasound scan showed that the heart structure and function of the fetus were normal. Cytogenetic analysis showed that the female karyotype was $47, \mathrm{XX}, \mathrm{t}(17 ; 22)$ (q21; q11), +21. The woman's husband had a normal male karyotype and was phenotypically normal. During this first pregnancy, an amniocentesis, which was done at 19 weeks, revealed that the fetal karyotype was $46, X X, t(17 ; 22)$ (q21; q11). Fluorescence in situ hybridization testing of amniotic fluid gave a normal result for chromosome 21 . The child was a phenotypically normal female baby.
\end{abstract}

Key words: Down syndrome; Fertility; Reciprocal translocation; Heredity 


\section{INTRODUCTION}

Down syndrome is a common genetic disorder, occurring in 1 of 700-800 births, with a gender ratio of three boys to two girls (Duchon et al., 2011). It has been reported that there are more than 217,800 cases a year across the world. The clinical picture of this syndrome is complex; more than 80 phenotypes have been observed in individuals, including intellectual disabilities with delayed learning and cognition, congenital anomalies such as congenital heart disease and childhood leukemia, and the appearance of an Alzheimer-like disease during aging (Fillon-Emery et al., 2004; Duchon et al., 2011; Wilcock et al., 2013).

Down syndrome accounts for approximately $2 \%$ of miscarriages. It seems to set a pattern of congenital heart defects, which are responsible for a large percentage of the main causes of death in adults with Down syndrome (Breia et al., 2014). However, recent birth cohorts of persons with Down syndrome showed a declining mortality rate and substantially longer survival, with life expectancy estimates increasing from 12 years of age in 1949 to nearly 60 years of age today (Merrick, 2000; Zhu et al., 2013). Zhu et al. (2013) observed that people with mosaicism for trisomy 21 showed a significant increase in survival compared to people with nonmosaic forms of Down syndrome. Thus, at present, most persons with Down syndrome survive into middle age. Researchers have begun to pay more attention to information on Down syndrome, such as the social conditions for adults with this disease, but little research has focused on fertility.

In the present study, we report a rare case of a child who inherited a chromosome 17 and 22 translocation from her mother, with the karyotype 47, XX, t(17; 22) (q21; q11), +21.

\section{MATERIAL AND METHODS}

\section{Case report}

A 30-year-old woman was referred for prenatal diagnoses because she had mental retardation (Figure 1a) and was pregnant. An ultrasound scan showed that the heart structure and function of the fetus were normal. The woman's husband was 32 years old, and physical examination showed that he was phenotypically normal. Cytogenetic analysis was performed on the peripheral blood lymphocytes of the couple. The proband's karyotype was 47,XX, t(17; 22) (q21; q11), +21. Her husband had a normal male karyotype.

During this first pregnancy, an amniocentesis, which was done at 19 weeks, revealed that the karyotype was $46, \mathrm{XN}, \mathrm{t}(17 ; 22)$ (q21; q11). Fluorescence in situ hybridization testing of amniotic fluid gave a normal result for chromosome 21 . The child was a phenotypically normal female baby.

The patients have given informed consent for publication of these results and the photograph in Figure 1.

\section{Cytogenetic analysis}

Chromosomal analyses were performed on fetal amniotic fluid and the patient's peripheral blood lymphocytes in our Genetics Laboratory. Metaphase chromosome spreads were studied by standard GTG banding procedures, which included using trypsin and Giemsa stain for G-band typing. At least 50 metaphases were evaluated. 


\section{RESULTS}

G-band karyotyping revealed that the proband has a balanced translocation between chromosomes 17 and 22 and, with the additional chromosome 21 (Figure 1b), carries the following karyotype: 47,XX, t(17; 22) (q21; q11), +21. Thus, she presents Down syndrome.

The karyotype of the amniotic fluid was 46,XX, t(17; 22) (q21; q11) mat (Figure 2).

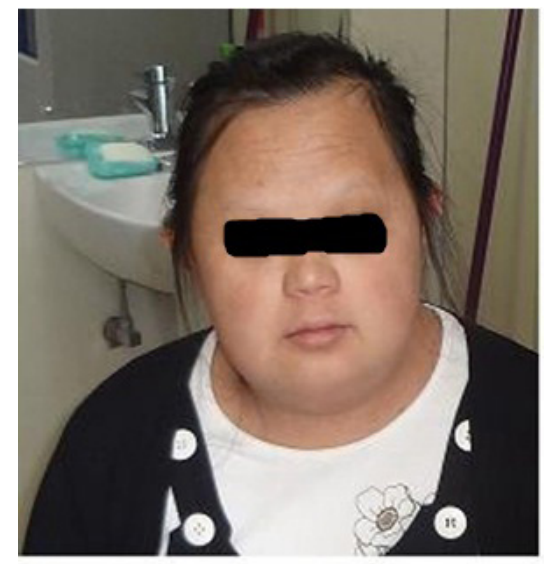

a

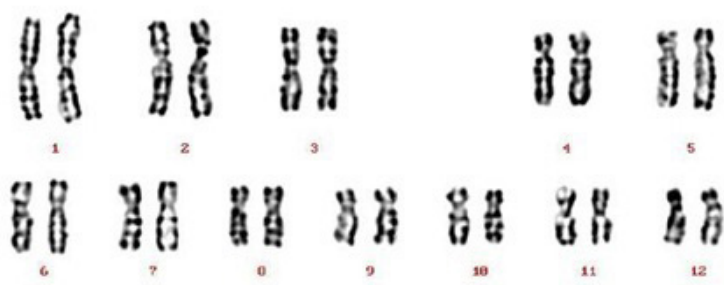

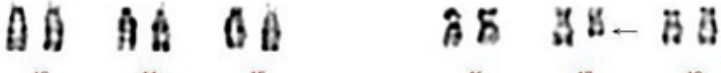
a 8 \& 8
คล

b

Figure 1. Facial features and chromosomal karyotype of the proband. a. Facial features of the female proband; $\mathbf{b}$. abnormal karyotype of the female: 47, XX, t(17; 22) (q21; q11), +21.

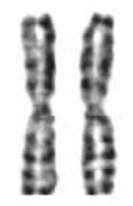

1

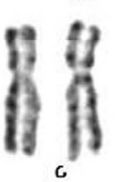

A

13

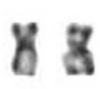

19

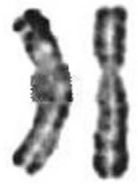

2
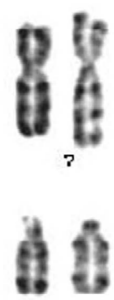

14

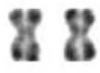

20

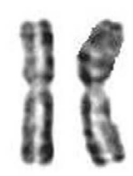

3

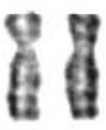

o

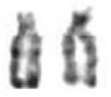

15
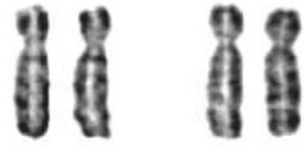

4

5

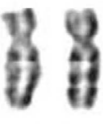

10

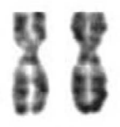

11
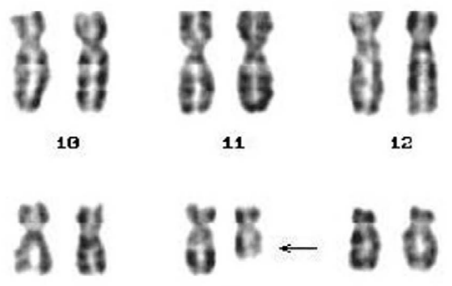

16

17

18

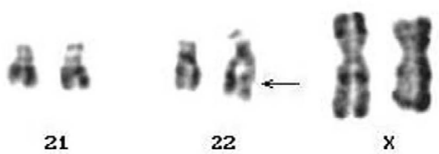

Figure 2. Karyotype of amniotic fluid cells: 46,XX, t(17; 22) (q21; q11) mat. 


\section{DISCUSSION}

Down syndrome is a chromosomal disorder caused by trisomy 21 . Its prevalence in Europe is about 9.8:10,000 live-born infants, while in the USA it is $8.5: 10,000$ newborns among mothers younger than 35 years of age and up to 55.3:10,000 newborns among mothers older than 35 years of age (Selim et al., 2013).

Although the coincidence of reciprocal translocation and trisomy may be seen in reciprocal translocation carrier families (Pazarbaşi et al., 2008), de novo cases are extremely rare. In the present study, we report a rare case of a 30-year-old woman who was referred for prenatal diagnoses and has the karyotype $47, \mathrm{XX}, \mathrm{t}(17 ; 22)(\mathrm{q} 21 ; \mathrm{q} 11),+21$, and who also had a pregnancy with the same reciprocal translocation. This finding is consonant with the observation that the most frequent reproductive outcome for a person with mosaicism for trisomy 21 is either a normal or trisomic chromosome 21 (Delhanty, 2011).

Chromosomal trisomy has been reported to occur in at least $4 \%$ of all pregnancies (Zühlke et al., 1994). Numerical chromosomal abnormalities, especially trisomies of chromosomes $13,18,21$, etc., are reported causes of pregnancy loss, neonatal deaths, and infertility.

Most information regarding fertility in people with mosaicism for Down syndrome is anecdotal. Zhu et al. (2013) reported that $7 \%$ of adults with mosaic Down syndrome have a child, compared to $1 \%$ of nonmosaic trisomic probands. Both males and females with mosaicism have been reported to demonstrate fertility. It has been reported that several females with Down syndrome have offspring who are chromosomally normal or have Down syndrome (Harris et al., 1982; Sheridan et al., 1989).

Down syndrome males have been reported to be infertile, but this may not always be true. Pradhan et al. (2006) reported a case of a nonmosaic Down syndrome male who fathered a chromosomally normal child. Zühlke et al. (1994) described a male with trisomy 21 who fathered a chromosomally normal female baby.

The presence of a balanced chromosomal translocation in the karyotype was ascertained for $0.6 \%$ of infertile couples and as many as $9.2 \%$ of fertile couples with recurrent miscarriages (Vozdova et al., 2012). Carriers of balanced translocations can suffer from infertility and are at high risk of conceiving chromosomally abnormal pregnancies that lead to recurrent spontaneous abortions or an affected live-born baby. Pazarbaşi et al. (2013) reported that one phenotypically normal female with a balanced translocation has three progenies: one with Down syndrome and the same translocation; another also carrying the same translocation, but without the additional chromosome 21; and one with a normal karyotype. There have also been reported reciprocal translocations, i.e., $t(17 ; 22)$, detected across generations (Subrt and Stirská, 1988; Dufke et al., 2001).

Individuals with balanced reciprocal translocations are known to have high rates of unbalanced gametes, to have impaired or reduced gametogenesis, to produce unbalanced embryos at high rates, and to have a greater chance of being infertile and/or a higher risk of conceiving chromosomally abnormal pregnancies that lead to recurrent spontaneous abortions or children with congenital anomalies (Fischer et al., 2010; Fiorentino et al., 2011; Mokánszki et al., 2012). Possible mechanisms whereby such translocations may have a phenotypic effect include cryptic unbalanced rearrangements, uniparental disomy, and disruption of putative genes at the breakpoints, unmasking recessive alleles on the normal homologs (Dufke et al., 2001). 
In conclusion, the findings on the family reported here will enable us to explain the behavior of segregation patterns. These findings can be used in providing genetic counseling, and preimplantation genetic diagnosis may be suggested.

\section{Conflicts of interest}

The authors declare no conflict of interest.

\section{ACKNOWLEDGMENTS}

We are grateful to all the patients and donors of blood samples. We express our sincere gratitude to all staff of the Genetics Laboratory for their excellent work. Research supported by the Jilin Province Development and Reform Commission (NDRC) Industry Technology Research and Development Projects (\#2011007-12).

\section{REFERENCES}

Breia P, Mendes R, Silvestre A, Gonçalves MJ, et al. (2014). Adults with Down syndrome: characterization of a Portuguese sample. Acta Med. Port. 27: 357-363.

Delhanty JD (2011). Inherited aneuploidy: germline mosaicism. Cytogenet. Genome Res. 133: 136-140.

Duchon A, Raveau M, Chevalier C, Nalesso V, et al. (2011). Identification of the translocation breakpoints in the Ts65Dn and Ts1Cje mouse lines: relevance for modeling Down syndrome. Mamm. Genome 22: 674-684.

Dufke A, Mayrhofer H, Enders H, Kaiser P, et al. (2001). Unusual chromosomal mosaicism as a cause of mental retardation and congenital malformations in a familial reciprocal translocation carrier, $\mathrm{t}(17 ; 22)$ (q24.2;q11.23). Cytogenet. Cell. Genet. 93: 168-170.

Fillon-Emery N, Chango A, Mircher C, Barbé F, et al. (2004). Homocysteine concentrations in adults with trisomy 21: effect of B vitamins and genetic polymorphisms. Am. J. Clin. Nutr. 80: 1551-1557.

Fiorentino F, Spizzichino L, Bono S, Biricik A, et al. (2011). PGD for reciprocal and Robertsonian translocations using array comparative genomic hybridization. Hum. Reprod. 26: 1925-1935.

Fischer J, Colls P, Escudero T and Munné S (2010). Preimplantation genetic diagnosis (PGD) improves pregnancy outcome for translocation carriers with a history of recurrent losses. Fertil. Steril. 94: 283-289.

Harris DJ, Begleiter ML, Chamberlin J, Hankins L, et al. (1982). Parental trisomy 21 mosaicism. Am. J. Hum. Genet. 34: 125-133.

Merrick J (2000). Incidence and mortality of Down syndrome. Isr. Med. Assoc. J. 2: 25-26.

Mokánszki A, Ujfalusi A, Balogh E, Sümegi A, et al. (2012). Meiotic segregation study of a novel t (3;6)(q21;q23) in an infertile man using fluorescence in situ hybridization (FISH). Syst. Biol. Reprod. Med. 58: 160-164.

Pazarbaşi A, Demirhan O, Turgut M, Güzel I, et al. (2008). Inheritance of a translocation between chromosomes 12 and 16 in a family with recurrent miscarriages and a newborn with Down syndrome carrying the same translocation. Genet. Couns. 19: 301-308.

Pazarbaşi A, Demirhan O, Alptekin D, Ozgunen F, et al. (2013). Inheritance of a chromosome 3 and 21 translocation in the fetuses, with one also having trisomy 21, in three pregnancies in one family. Balkan J. Med. Genet. 16: 91-96.

Pradhan M, Dalal A, Khan F and Agrawal S (2006). Fertility in men with Down syndrome: a case report. Fertil. Steril. 86: 1765.e1-1765.e3.

Selim Kolgeci, Jehona Kolgeci, Mehmedali Azemi, Ruke Shala-Beqiraj, et al. (2013). Cytogenetic Study in Children with Down Syndrome Among Kosova Albanian Population Between 2000 and 2010. Mater. Sociomed. 25: 131-135.

Sheridan R, Llerena J Jr, Matkins S, Debenham P, et al. (1989). Fertility in a male with trisomy 21. J. Med. Genet. 26: 294-298.

Subrt I and Stirská K (1988). Familial translocation t $(17 ; 22)$, including the segregation in five consecutive abortuses. Hum. Genet. 80: 195-196.

Vozdova M, Kasikova K, Oracova E, Prinosilova P, et al. (2012). The effect of the swim-up and hyaluronan-binding methods on the frequency of abnormal spermatozoa detected by FISH and SCSA in carriers of balanced chromosomal 
translocations. Hum. Reprod. 27: 930-937.

Wilcock DM and Griffin WS (2013). Down's syndrome, neuroinflammation, and Alzheimer neuropathogenesis. J. Neuroinflam. 10: 84

Zhu JL, Hasle H, Correa A, Schendel D, et al. (2013). Survival among people with Down syndrome: a nationwide population-based study in Denmark. Genet. Med. 15: 64-69.

Zühlke C, Thies U, Braulke I, Reis A, et al. (1994). Down syndrome and male fertility: PCR-derived fingerprinting, serological and andrological investigations. Clin. Genet. 46: 324-326. 